\title{
Method of evaluating the impact of landfill leachate on groundwater quality
}

\author{
Kazimierz Szymański • Beata Janowska • \\ Anna Iżewska • Robert Sidelko • Izabela Siebielska
}

Received: 30 June 2017 / Accepted: 31 May 2018 / Published online: 20 June 2018

(C) The Author(s) 2018

\begin{abstract}
Closed municipal and industrial waste landfill sites create potential hazard of ground water pollution. Pollutants that occur in leachate infiltrate to the soil substratum, where they are carried to in underground water. A municipal waste landfill substratum can be used for elimination of pollutants contained in leachates. Model research was performed with the use of a sand bed and artificially prepared leachates. Efficiency of filtration in a bed of defined thickness was assessed based on change of COD value. Results of the model tests have indicated that the mass of pollutants contained in leachate filtered through porous ground layer depends on the mass of supplied pollutants, intensity of supplied leachate, and layer thickness. Increase of the mass of pollutants supplied to a unit area of ground layer causes reduction of the relative value of COD mass. The method of evaluation of quality of water seeping through the aeration layer presented in this paper allows for estimation of the flowing out pollutants mass. Based on the test results obtained, efficiency of purification in the aeration zone can be assessed; likewise, safe thickness of the filtration layer under the landfill site can be designed.
\end{abstract}

K. Szymański · B. Janowska $(\bowtie) \cdot$ R. Sidełko · I. Siebielska

Faculty of Civil Engineering, Environmental and Geodetic Sciences, Department Waste Management, Koszalin University of Technology, ul. Śniadeckich 2, 75-453 Koszalin, Poland e-mail: beata.janowska@tu.koszalin.pl

A. Iżewska

Faculty of Civil Engineering and Architecture, Department of Sanitary Engineering, West Pomeranian University of Technology Szczecin, Al. Piastów 50, 70-311 Szczecin, Poland
Keywords Landfill leachate $\cdot$ Aeration zone $\cdot$ Water pollution $\cdot$ Migration

\section{Introduction}

Municipal waste landfill sites, which are placed on permeable soil, create potential hazard for purity of ground waters located in their neighbourhood (Szymański et al. 2007). Type and quantity of pollutants migrating from any landfill site to ground waters depends mainly on the type of landfilled waste, its quantity, site's geometry, physical condition of the substratum, and thickness of the aeration zone (Han et al. 2013; Li et al. 2012; Nowak et al. 2016; Regadio et al. 2012; Reyes-López et al. 2008). Mass of the pollutants migrating from the aeration zone to ground waters can be estimated by application of various methods (Koda et al. 2009; Szymański and Siebielska 2000; Wysocka 2015). The best possible case takes into consideration observations performed on real objects. Such methods are usually time-consuming and expensive, particularly if they are applied in closed objects. The degree of pollution of underground waters can be estimated based on model test results (Burn and Engesgaard 2002; Thornton et al. 2005). Model tests should be performed taking into account the conditions of landfill location, qualitative and quantitative parameters of landfill leachate, and underground water (Szymański and Janowska 2016; Tsanis 2006; Tałałaj and Dzienis 2007; Zhu et al. 2013). An attempt was made in this paper to estimate migration of leachate to the aeration zone based on 
artificially modelled soil substratum and artificial landfill leachate.

\section{Theoretical basis for the process of migration of leachate to ground waters}

Methods of determination of pollutant concentrations in ground waters flowing in the water-bearing layer featuring thickness $a$, with velocity v, under a landfill featuring width $b$ (Fig. 1), were described in many publications (Burn and Engesgaard 2002; Islam and Singhal 2004; Lacerda et al. 2014; Li et al. 2012; Nayak et al. 2007; Regadio et al. 2012; Tsanis 2006). Such calculations are based on determination of elementary volumes of leachate filtrated through the aeration zone $d V_{f}$, flowing within period $d t$, into ground water surface $d b$ of $1.0 \mathrm{~m}^{2}$. In such case, the following formula can be used (1):

$d V_{f}=v_{a} \cdot d b \cdot 1.0 \cdot d t$

where $v_{\mathrm{a}}$ means velocity of leachate flow in the aeration zone.

Total volume of leachate, which flows into that area, during its flow with velocity $\mathbf{v}$, at the distance equal to the landfill site width, can be determined from the following formula (2):

$V_{f}=v_{a} \cdot \int_{0}^{b} d b \cdot \int_{0}^{T} d t=v_{a} \cdot b \cdot T$

Time $\boldsymbol{T}$ is equivalent to a period in which front of the considered ground water surface will move by distance $\boldsymbol{b}$. This can be calculated from the following formula:

$T=\frac{b}{v}$

therefore, volume of leachate arriving to a single square meter of water surface will be equal to:

$V_{f}^{\prime}=\frac{v_{a}}{v} \cdot b$

Therefore, concentration of pollutants in the ground water flowing out of the landfill site area (without taking into account of self-purification of those waters during their flow under the landfill site) can be calculated from the following formula:

$C=\frac{c_{f} \cdot v_{f}^{\prime}}{a}=C_{f} \frac{v_{a} \cdot b}{v \cdot a}$ where $\mathbf{C}_{\mathbf{f}}$ is a concentration of any pollution indicator in water flowing out from the aeration zone.

The approximate liquid flow velocity in the aeration zone $\boldsymbol{v}_{\boldsymbol{a}}$ can be calculated from a formula proposed by Szestakow (1973):

$v_{a}=\frac{1}{n_{0}} \cdot \omega^{\left(1-\frac{1}{n}\right)} \cdot k^{\frac{1}{n}}$

where particular symbols define:

$\mathrm{n}_{\mathrm{o}}$ active soil porosity,

$\omega$ intensity of leachate outflow from landfill,

$\mathrm{k}$ coefficient of permeability of the aeration zone soil,

$\mathrm{n}$ a coefficient, which in this calculation assumes value of $n=3$.

Therefore, the approximate leachate velocity value in the aeration zone is

$v_{a}=\frac{1}{n_{0}} \cdot \sqrt[3]{\omega^{2} \cdot k}$

Analysis of formula (5) leads to an observation that concentration of pollutants in ground water increases with increase of concentration of inflowing leachate $\left(\mathrm{C}_{\mathrm{f}}\right)$, velocity of its flow in the aeration zone and landfill size. An assumption has been made that landfill leachate migrates in the same direction as ground waters flow. Underground water pollutant concentration is contingent also upon conditions of their flow. The lower the volumetric output of those waters, the higher the probability of their pollution.

Concentration of pollution in ground water flowing outside the landfill perimeter can be calculated much easier if test results for aeration zone purification properties (Figs. 2, 3, and 4) are available:

$Q=\frac{m_{d}}{F \cdot t}=\frac{m_{d}^{\prime}}{t}$

where particular symbols define:

$\mathrm{m}_{\mathrm{d}} \quad$ mass of supplied pollutants

$\mathrm{m}_{\mathrm{d}}$ mass of pollutant supplied into soil unit area.

Assuming permanent load of supplied leachate $(Q)$, mass of pollutant supplied to a single square meter of the aeration zone $F$ (sand layer) can be calculated for any period $t$ : 
Fig. 1 Diagram of pollutants inflowing into underground waters (aeration zone) (Szymański 1987)

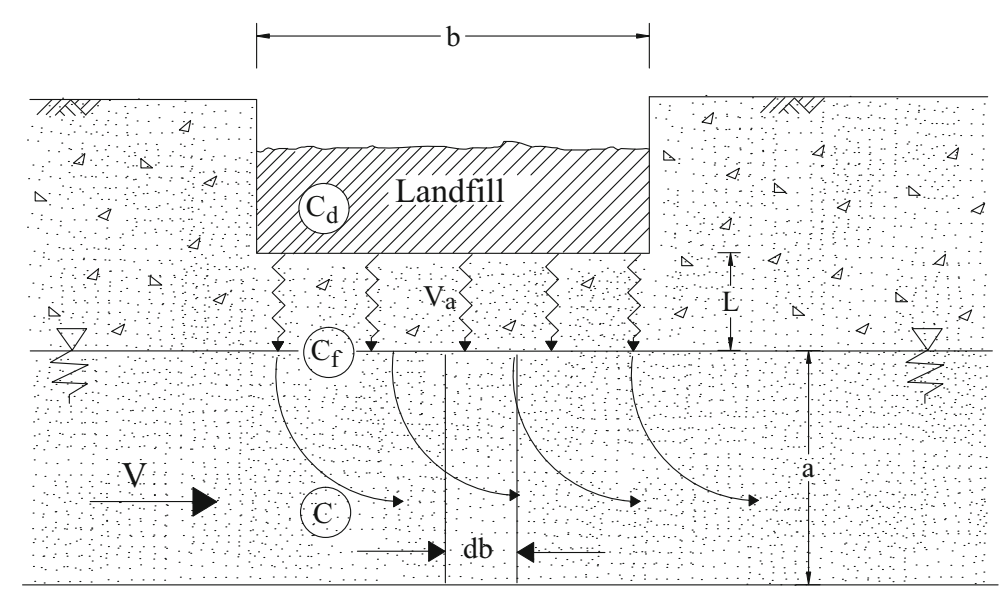

$\left(m_{d}^{\prime}\right)_{t}=Q \cdot t$

Based on known ground water flow time $T$ at distance $b$, mass of supplied pollutants (in period $t+T$ ) can be determined from the following formula:

$$
\left(m_{d}^{\prime}\right)_{t+T}=Q(t+T)
$$

Using model test results, as a relationship between $m_{f}^{\prime}$ (mass of pollutant filtered through unit area) and $\boldsymbol{m}_{d}{ }^{\prime}$, mass of pollutants inflowing to ground water during their flow under the landfill $\left(m_{f}^{\prime}\right)_{T}$ can be determined. Therefore, concentration of pollutants in water flowing beyond the landfill perimeter will be equal to:

$C=\frac{\left(m_{f}^{\prime}\right)_{T}}{a}$

If a linear relation would occur between $m_{f}$ and $m_{d}{ }^{\prime}$ values, then, values of $\left(m_{f}\right)_{T}$ will be constant and independent of time. In the event that the relationship between those values would be described by another function, values $\left(m_{f}\right)_{T}$ will change in time of landfill operation period $(t)$. In such case, this variable should be taken into account in calculation of pollutant concentration in ground water flowing out of the considered object area.

\section{Materials and methods}

Model tests representing infiltration of leachate through the aeration zone were performed in order to define the qualitative and quantitative relationship between the mass of pollutants both supplied and carried away from the porous medium (An et al. 2013; Lacerda et al. 2014; Papapertridis and Paleologos 2012; Szymański and Janowska 2016). Medium sand and artificially prepared leachates were used to fill in the filtration columns. The physico-chemical composition of the leachates was selected in such way so as to reflect content of selected indicators in real leachates (Castrillon et al. 2010; Szymański and Nowak 2012). The variable parameters were intensity of supplied leachates $\boldsymbol{\omega}$ (leachate volume per unit area and unit of time), mass of supplied pollutants $m_{d}$, and soil thickness $l$. Analysis of changes in the mass of pollutants $m_{f}$ filtered through the model layer was performed using one of the indicators describing landfill leachate such as $\mathrm{COD} \mathrm{K}_{2} \mathrm{Cr}_{2} \mathrm{O}_{7}$ (Kulikowska and Klimiuk 2008).

Medium sand taken from the municipal landfill area was used in the tests.

Its maximum and minimum density values were $\left(\rho_{d}\right)_{\max }=1.79 \cdot 10^{3} \mathrm{~kg} \cdot \mathrm{m}^{-3}$ and $\left(\rho_{d}\right)_{\min }=1.63 \cdot 10^{3} \mathrm{~kg} \cdot \mathrm{m}^{-3}$ respectively. The maximum sand density at humidity $w=$ $2.3 \%$, in which it was used in model tests, was $\rho_{\max }=$ $1.83 \cdot 10^{3} \mathrm{~kg} \mathrm{~m}^{-3}$. Approximately $2.0 \mathrm{~kg}$ of sand was being poured into the column and then compacted with $1.0 \mathrm{~kg}$ compactor, which was dropped ten times from the height of approximately $0.5 \mathrm{~m}$. Once the bed was formed up to a defined height, its depth was measured and density was calculated (Szyszkowski, 2000). Three series of tests were performed. Each series differed in bed thickness, which was $l_{1}=0.3 \mathrm{~m}, l_{2}=0.6 \mathrm{~m}, l_{3}=0.9 \mathrm{~m}$ respectively. In each test, series leachate was supplied everyday into respective columns with variable intensity: $\omega_{1}=0.026 \mathrm{~m}^{3} \cdot \mathrm{m}^{-2} \cdot \mathrm{d}^{-1}, \omega_{2}=0.052 \mathrm{~m}^{3} \cdot \mathrm{m}^{-2} \cdot \mathrm{d}^{-1}, \omega_{3}=$ $0.104 \mathrm{~m}^{3} \cdot \mathrm{m}^{-2} \cdot \mathrm{d}^{-1}$, and $\left(\omega_{2}=2 \cdot \omega_{1}, \omega_{3}=4 \cdot \omega_{1}\right)$. Each day a specified dose of leachate was supplied to the top surface of the filter bed. Therefore, to the first filtration column, in each test series, following volumes of leachate 
were supplied: $v_{1}=195 \cdot 10^{-6} \mathrm{~m}^{3}$, to the second $v_{2}=$ $390 \cdot 10^{-6} \mathrm{~m}^{3}$, and to the third $v_{3}=780 \cdot 10^{-6} \mathrm{~m}^{3}$ respectively. During the entire test procedure, approximately 50 doses of leachate were supplied to each column. COD $\mathrm{K}_{2} \mathrm{Cr}_{2} \mathrm{O}_{7}$ values were then determined in the leachates and filtrates (Szyszkowski, 2000).

\section{Results and discussion}

Values of pollutant loads in particular experiments are given based on COD example (Figs. 2, 3, and 4). Figures 2, 3, and 4 show mass of pollutants contained in the filtrate depending on the number of supplied doses of leachate for all three series of tests. To each layer of given series $(l=$ const), various volumes of leachate were supplied $\left(V_{1}, V_{2}\right.$, or $\left.V_{3}\right)$, so intensity $\left(\omega_{1}, \omega_{2}\right.$ or $\left.\omega_{3}\right)$ and mass of supplied pollutants $\left(m_{d}\right)$ was different. Mass of pollutants in the filtrate depends on thickness of the bed and intensity of leachate supplied.

In each test series, there was a different value of pollutant mass in a dose of supplied leachate. Pollutant load shows, depending on increase of leachate volume and intensity, a growing trend of the mass of filtered pollutants.

Increasing of volume and decreasing of leachate supply intensity extends the test time considerably. Constant increase of the mass of filtered pollutants (Figs. 2, 3, and 4, Table 1) was observed for certain values of supplied leachate $\boldsymbol{m}_{\boldsymbol{d}}$. In the final stage of the experiments, $\Delta \mathrm{m}_{\mathrm{f}} / \Delta \mathrm{m}_{\mathrm{d}}$ ratio assumed constant values. Therefore, relationship obtained for slightly higher $\boldsymbol{m}_{\boldsymbol{d}}$ values than those applied in the tests can be extrapolated. One can expect that if the layer thickness will tend to zero, mass of filtrated pollutants will approach the mass of pollutants supplied. However, if intensity of supplied leachate will approach zero, also mass of the filtered impurities will approach zero. Assuming correctness of this reasoning, the following assumptions were made:

$$
\begin{array}{cl}
\text { if } I=0 \text { to } m_{f}=m_{d} & \text { (if } y=0 \text { to } Z=x) \\
\text { if } \omega=0 \text { to } m_{f}=0 & \text { (if } w=0 \text { to } Z=0)
\end{array}
$$

where $\boldsymbol{Z}$-regression function coefficients calculated for the relationship between the mass of pollutants supplied and filtered through the layer of medium sand (Table 2). Therefore, function $Z=Z(x, y, w)$ can be expressed in the following way:

$Z(x, y, w)=w\left[Z_{1}^{\prime}(x, y) \cdot K_{1}^{\prime}+Z_{2}^{\prime}(x, y) \cdot K_{2}^{\prime}+Z_{3}^{\prime}(x, y) \cdot K_{3}^{\prime}\right]$

$\boldsymbol{Z}$ function values are taken for given pollution indicator, depending on layer thickness $y$ and intensity $w$, from Table 2. The parameters of regression function presented in said table were calculated for laboratory conditions in which leachate flew through area of $F=$ $0.0075 \mathrm{~m}^{2}$. In calculations performed for $1.0 \mathrm{~m}^{2}$, area those parameters should be corrected. If linear relationship will be adopted (in the case of COD) between the mass supplied and filtered, then coefficient $a$ will not change whereas coefficient $b^{\prime}$ at the free term can be calculated from the following formula:
Fig. 2 Pollutant load contained in the filtrate after flowing through $0.30 \mathrm{~m}$ bed expressed by $\mathrm{COD} \mathrm{K}_{2} \mathrm{Cr}_{2} \mathrm{O}_{7}$

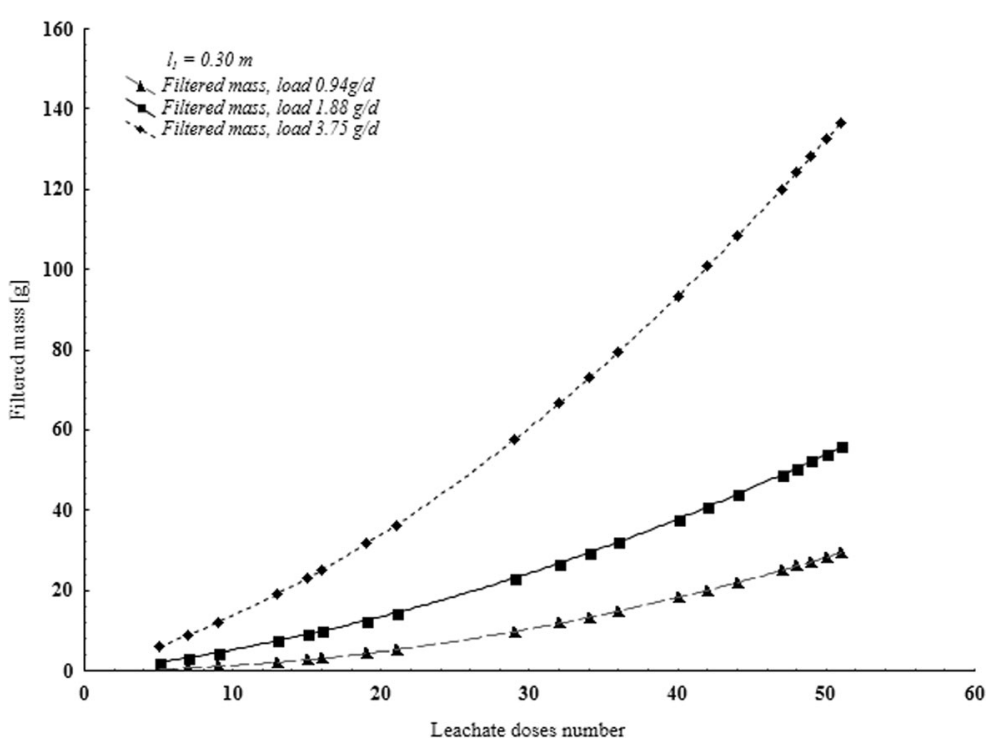


Fig. 3 Pollutant load contained in the filtrate after flowing through $0.60 \mathrm{~m}$ bed expressed by $\mathrm{COD} \mathrm{K}_{2} \mathrm{Cr}_{2} \mathrm{O}_{7}$ $b^{\prime}=b \cdot F=b \cdot 0.0075$

Taking into consideration the influence of all three variables $\left(\mathrm{m}_{\mathrm{d}}, l, \omega\right)$, formula (12) will take the following form:

$$
Z=0.0034[7.413 \cdot 92.61+10.882 \cdot(-32.27)+12.677 \cdot 2.60]
$$

Finally, COD mass inflowing during a single day to ground water from $1.0 \mathrm{~m}^{2}$ of the landfill will be

$\Delta Z=\left(\Delta m_{f}^{\prime}\right)_{C O D}=1.252 \frac{g}{m^{2}} d$.

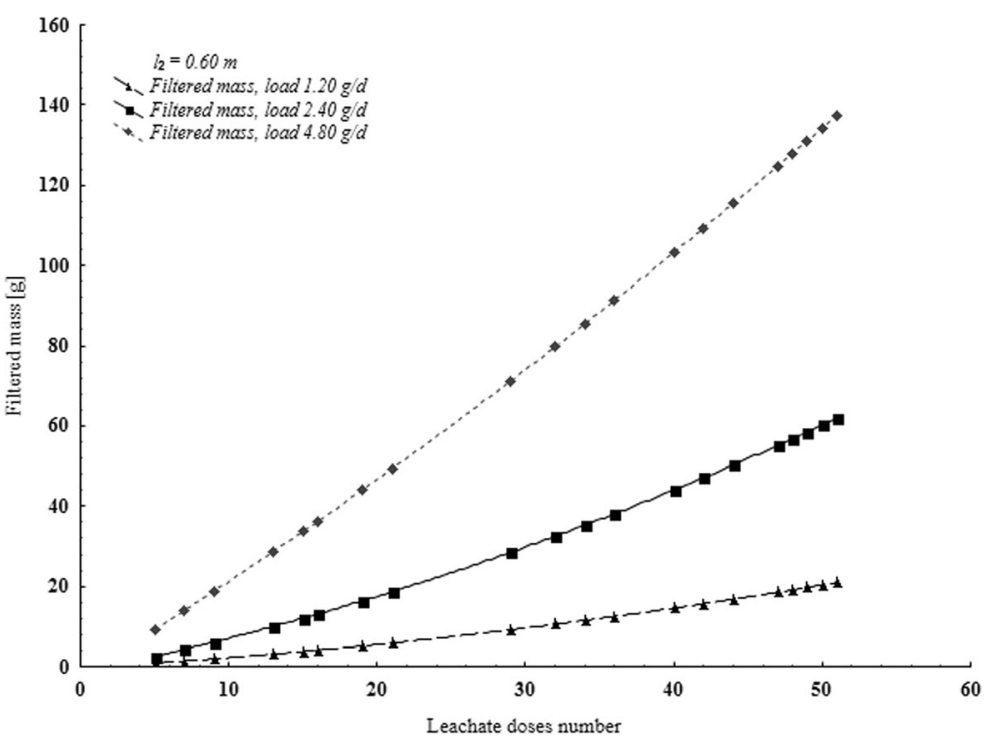

Determined regression functions indicate compatibility with linear model of empiric values of variable $m_{f}$ ' $\mathrm{m}_{\mathrm{f}}^{\prime}$. Determined regression functions allow for estimation of qualitative and quantitative influence of analysed independent variables $\left(m_{d}^{\prime}, l, \omega\right)$ onto values of the mass of pollutants flowing out from the medium sand layer. The presented model can only be used to estimate leaching of contaminants from landfills if the landfill subsoil is made of sandy soil. These model have been verified in the studies, which were presented by Szymański and Janowska (2016) and Szymański et al. (2017).
Fig. 4 Pollutant load contained in the filtrate after flowing through $0.90 \mathrm{~m}$ bed expressed by $\mathrm{COD} \mathrm{K}_{2} \mathrm{Cr}_{2} \mathrm{O}_{7}$

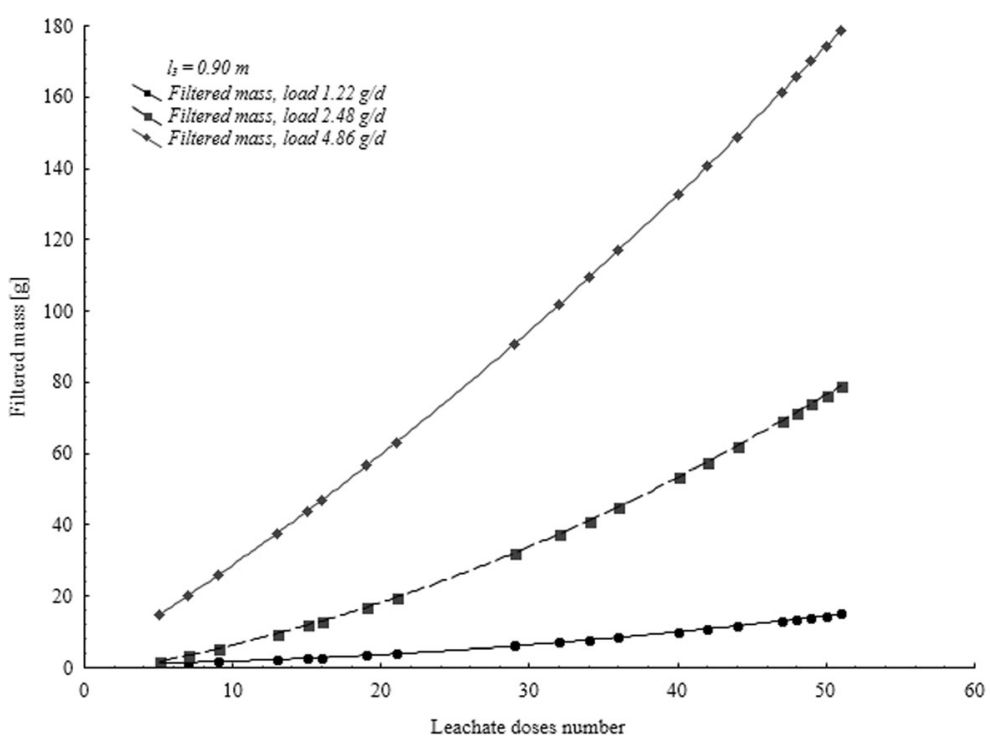


Table 1 Regression function coefficients calculated for the relationship between mass of pollutants supplied and filtered through the medium sand bed $\left(F=0.0075 \mathrm{~m}^{2}\right)$

\begin{tabular}{|c|c|c|c|c|c|c|c|c|c|c|c|c|}
\hline \multirow{3}{*}{$\begin{array}{l}\text { Pollution } \\
\text { Indicator }\end{array}$} & \multirow{3}{*}{$\begin{array}{l}\text { Thickness } \\
{[\mathrm{m}]}\end{array}$} & \multirow{3}{*}{$\begin{array}{l}\text { Intensity } \\
{\left[\mathrm{m}^{3} \cdot \mathrm{m}^{-2} \cdot \mathrm{day}^{-1}\right]}\end{array}$} & \multicolumn{3}{|c|}{$Z=\mathrm{ax}^{\mathrm{b}}$} & \multicolumn{3}{|c|}{$Z=\mathrm{ax}+\mathrm{b}$} & \multicolumn{4}{|c|}{$Z=\mathrm{ax}^{2}+\mathrm{bx}+\mathrm{c}$} \\
\hline & & & \multicolumn{3}{|c|}{$\left(\mathrm{m}_{\mathrm{f}}=\mathrm{a} \mathrm{m}_{\mathrm{d}}^{\mathrm{b}}\right)$} & \multicolumn{3}{|c|}{$\left(m_{\mathrm{f}}=\mathrm{a} \mathrm{m}_{\mathrm{d}}+\mathrm{b}\right)$} & \multicolumn{4}{|c|}{$\left(\mathrm{m}_{\mathrm{f}}=\mathrm{a} \mathrm{m}_{\mathrm{d}}^{2}+\mathrm{b} \mathrm{m}_{\mathrm{d}}+\mathrm{c}\right)$} \\
\hline & & & $a$ & $b$ & $R^{2}$ & $a$ & $b$ & $R^{2}$ & $a$ & $b$ & $c$ & $R^{2}$ \\
\hline 1 & 2 & 3 & 4 & 5 & 6 & 7 & 8 & 9 & 10 & 11 & 12 & 13 \\
\hline \multirow[t]{9}{*}{ COD } & 0.3 & 0.026 & 0.042 & 1.63 & 0.925 & 0.46 & -2.77 & 0.978 & 0.009 & 0.049 & 0.755 & 0.996 \\
\hline & & 0.052 & 0.043 & 1.6 & 0.982 & 0.57 & -5.38 & 0.992 & 0.003 & 0.269 & -0.629 & 0.999 \\
\hline & & 0.104 & 0.061 & 1.48 & 0.993 & 0.69 & -11.02 & 0.995 & 0.002 & 0.409 & -2.958 & 0.999 \\
\hline & 0.6 & 0.026 & 0.119 & 1.22 & 0.942 & 0.38 & -4.07 & 0.971 & 0.006 & -0.068 & 2.967 & 0.999 \\
\hline & & 0.052 & 0.06 & 1.45 & 0.007 & 0.59 & -11.02 & 0.997 & 0.001 & 0.426 & -5.834 & 0.999 \\
\hline & & 0.104 & 0.102 & 1.32 & 0.998 & 0.67 & -20.49 & 0.997 & 0.001 & 0.452 & -6.601 & 0.999 \\
\hline & 0.9 & 0.026 & 0.039 & 1.3 & 0.852 & 0.2 & -2.39 & 0.946 & 0.005 & -0.13 & 1.748 & 0.998 \\
\hline & & 0.052 & 0.103 & 1.34 & 0.979 & 0.62 & -9.48 & 0.992 & 0.002 & 0.353 & -3.162 & 0.995 \\
\hline & & 0.104 & 0.344 & 1.23 & 0.997 & 0.69 & -6.61 & 0.998 & 0.001 & 0.738 & -8.995 & 0.998 \\
\hline
\end{tabular}

\section{Conclusion}

The proposed method of estimation of mass of pollutants penetrating through the aeration zone to ground waters can make the first approximation in solution of practical problems (Islam and Singhal 2004; Nayak et al. 2007). However, this method does not allow for direct identification of the processes that occur during flow of polluted water through a porous medium. Yet, use of the real soil in model tests (taken from the substratum of the tested landfill) and representative composition of a leachate, allows for obtaining reliable

Table 2 Linear function of multiple regression for selected indicator describing leachate supplied to an exemplary filtration bed featuring thickness of $0.90 \mathrm{~m}$

\begin{tabular}{lll}
\hline $\begin{array}{l}\text { Pollution } \\
\text { indicator }\end{array}$ & $\begin{array}{l}\text { Regression function } \\
\mathrm{m}_{\mathrm{f}}=\mathrm{m}_{\mathrm{f}}^{\prime}\left(\mathrm{m}_{\mathrm{d}}, l, \omega\right)\end{array}$ & $\begin{array}{l}\text { Multiple } \\
\text { correlation } \\
\text { coefficient } R^{2}\end{array}$ \\
\hline $\mathrm{COD} \mathrm{K}_{2} \mathrm{Cr}_{2} \mathrm{O}_{7}$ & $\begin{array}{r}\mathrm{m}_{\mathrm{f}}{ }^{\prime}=0.54 \mathrm{~m}_{\mathrm{d}}{ }^{\prime}+291.751 \\
+25,485.90 \omega-2162.76\end{array}$ & 0.9957 \\
\hline
\end{tabular}

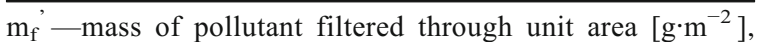
$\mathrm{m}_{\mathrm{d}}$ - mass of pollutant supplied into soil unit area $\left[\mathrm{g} \cdot \mathrm{m}^{-2}\right]$, $l$-layer thickness [m], $\omega$-intensity of leachate supply $\left[\mathrm{m}^{3} \cdot \mathrm{m}^{-2}\right.$ day $\left.^{-1}\right]$ information on pollution of ground water in the considered specific case (An et al. 2013; Cuevas et al. 2012). The method of assessment of quality of water seeping through the aeration layer presented in this paper allows for estimation of the mass of outflowing pollutants and intensity of supply of pollutants to the saturation layer.

Based on the test results obtained, efficiency of purification of the aeration zone can be assessed. Safe thickness of the filtration layer under the landfill can also be designed. At the same time, a forecast of the speed of propagation of the pollution zone in ground water and the distance of such zone front from the landfill in various periods of its operation can be forecast. The model test results for migration of landfill leachate in soil substratum, interpreted by application of the linear function of multiple regression, indicate a possibility of their adaptation to specific soil conditions (Szymański and Janowska 2016). They allow also for forecasting of the types of pollution that could occur in landfill leachate infiltrating to the substratum composed of porous materials and to underground waters.

Compliance with ethical standards The present research is part of the project no. 504.01.15 (statutory research).

Conflict of interest The authors declare that they have no conflict of interest. 
Ethical approval This paper does not contain any studies with human participants or animals performed by any of the authors.

Informed consent Informed consent was obtained from all individual participants included in the study.

Open Access This article is distributed under the terms of the Creative Commons Attribution 4.0 International License (http:// creativecommons.org/licenses/by/4.0/), which permits unrestricted use, distribution, and reproduction in any medium, provided you give appropriate credit to the original author(s) and the source, provide a link to the Creative Commons license, and indicate if changes were made.

\section{References}

An, D., Jiang, Y., Xi, B., Ma, Z., Yang, Y., Yang, Q., Li, M., Zhang, J., Bai, S., \& Jiang, L. (2013). Analysis for remedial alternatives of unregulated municipal solid waste landfills leachate-contaminated groundwater. Frontiers of Earth Science, 7(3), 310-319.

Brun, A., \& Engesgaard, P. (2002). Modelling of transport and biogeochemical processes in pollution plumes: literature review and model development. Journal of Hydrology, 256(34), 211-227.

Castrillón, L., Fernández-Nava, Y., Ulmanu, M., Anger, I., \& Marañón, E. (2010). Physico-chemical and biological treatment of MSW landfill leachate. Waste Management, 30(2), 228-235.

Cuevas, J., Ruiz, A. I., de Soto, I. S., Sevilla, T., Procopio, J. R., Da Silva, P., Gismera, M. J., Regadío, M., Sánchez Jiménez, N., Rodríguez Rastrero, M., \& Leguey, S. (2012). The performance of natural clay as a barrier to the diffusion of municipal solid waste landfill leachates. Journal of Environmental Management, 95, S175-S181.

Han, D. M., Tong, X. X., Jin, M. G., Hepburn, E., Tong, C. S., \& Song, X. F. (2013). Evaluation of organic contamination in urban groundwater surrounding a municipal landfill, Zhoukou, China. Environmental Monitoring and Assessment, 185(4), 3414-3444.

Islam, J., \& Singhal, N. (2004). A laboratory study of landfill leachate transport in soils. Water Research, 38(8), 20352042.

Koda, E., Wiencław, E., \& Martelli, L. (2009). Transport modelling and monitoring research use for efficiency assessment of vertical barrier surrounding old sanitary landfill. Annals of Warsaw University of Life Sciences - SGGW Land Reclamation, 41, 41-48.

Kulikowska, D., \& Klimiuk, E. (2008). The effect of landfill age on municipal leachate composition. Bioresource Technology, 99(13), 5981-5985.

Lacerda, C. V., Ritter, E., da Costa Pires, J. A., \& de Castro, J. A. (2014). Migration of inorganic ions from the leachate of the Rio das Ostras landfill: a comparison of three different configurations of protective barriers. Waste Management, 34(11), 2285-2291.

Li, Y., Li, J., Chen, S., \& Diao, W. (2012). Establishing indices for groundwater contamination risk assessment in the vicinity of hazardous waste landfills in China. Environmental Pollution, 165, 77-90. https://doi.org/10.1016/j.envpol.2011.12.042.

Nayak, S., Sunil, B. M., \& Shrihari, S. (2007). Hydraulic and compaction characteristics of leachate-contaminated lateritic soil. Engineering Geology, 94(3-4), 137-144.

Nowak, R., Włodarczyk-Makuła, M., Wiśniowska, E., \& Grabczak, K. (2016). The comparison of the effectiveness of pre-treatment processes of landfill leachate. Annual Set The Environment Protection, 18, 122-133 (in Polish).

Papapetridis, K., \& Paleologos, E. K. (2012). Sampling frequency of groundwater monitoring and remediation delay at contaminated sites. Water Resources Management, 26(9), 26732688.

Regadío, M., Ruiz, A. I., de Soto, I. S., Rodriguez Rastrero, M., Sánchez, N., Gismera, M. J., Sevilla, M. T., da Silva, P., Rodríguez Procopio, J., \& Cuevas, J. (2012). Pollution profiles and physicochemical parameters in old uncontrolled landfills. Waste Management, 32(3), 482-497.

Reyes-López, J. A., Ramírez-Hernández, J., Lázaro-Mancilla, O., Carreón-Diazcontia, C., \& Martín-Loeches Garrido, M. (2008). Assessment of groundwater contamination by landfill leachate: a case in México. Waste Management, 28(1), S33S39.

Szestakow, W.H., 1973. The dynamics of groundwater, Izd. Moskowskogo Uniwersiteta, Moskwa. (in Russian).

Szymański, K. (1987). The migration of leachate from municipal landfills in the soil, Wydawnictwo Wyższej Szkoły Inżynierskiej, Koszalin. (in Polish).

Szymański, K., \& Janowska, B. (2016). Migration of pollutants in porous soil environment. Archives of Environmental Protection, 42(3), 87-95.

Szymański, K., \& Nowak, R. (2012). Transformations of leachate as a result of technical treatment at municipal waste landfills. Annual Set the Environment Protection, 14, 337-350 (in Polish).

Szymański, K., Sidełko, R., Janowska, B., \& Siebielska, I. (2007). Monitoring of waste landfills. Scientific Papers of the Faculty of Civil and Environmental Engineering, 23, 75133 (in Polish).

Szymański, K., Sidełko, R., Janowska, B., Siebielska, I., \& Walendzik, B. (2017). Modelling the parameters of migration of chemical pollutants in the soil base of municipal landfills. Annual Set the Environment Protection, 19, 651-667 (in Polish).

Szymański, K., \& Siebielska, I. (2000). Evaluation of ground water pollution: analytical problems. Ochrona Środowiska, 76, 15-18 (in Polish).

Szyszkowski, P. (Ed.). (2000). Guide. The test methods and recognizing the impact on soil and water environment solid waste landfills. Warszawa: Oficyna Wydawnicza El-Press (in Polish).

Tałałaj, I. A., \& Dzienis, L. (2007). Influence of leachate on quality of underground waters. Polish Journal of Environmental Studies, 16(1), 139-144. 
Thornton, S. F., Tellam, J. H., \& Lerner, D. N. (2005). Experimental and modelling approaches for the assessment of chemical impacts of leachate migration from landfills: a case study of a site on the Triassic sandstone aquifer in the UK East Midlands. Geotechnical and Geological Engineering, 23(6), 811-829.

Tsanis, I. K. (2006). Modeling leachate contamination and remediation of groundwater at a landfill site. Water Resources Management, 20(10), 109-132.
Wysocka, M. E. (2015). Influence of location of landfills on groundwater quality. Annual Set The Environment Protection, 17, 1074-1093 (in Polish).

Zhu, N., Ku, T., Li, G., \& Sang, N. (2013). Evaluating biotoxicity variations of landfill leachate as penetrating through the soil column. Waste Management, 33(8), 1750-1757. 